\title{
Giant Right Coronary Artery to Coronary Sinus Fistula
}

Lamees El Nihum ${ }^{1}$, M. Mujeeb Zubair ${ }^{2}$, Ponraj Chinnadurai ${ }^{3}$, and Thomas E.

MacGillivray $^{1}$

${ }^{1}$ Houston Methodist Debakey Heart \& Vascular Center

${ }^{2}$ Cedars-Sinai Medical Center

${ }^{3}$ Siemens Medical Solutions USA Inc

February 1, 2022

\begin{abstract}
Coronary artery fistulas are rare congenital anomalies for which the ideal management strategies remain under study, with surgical repair being the mainstay of treatment in complex, aneurysmal fistulas.
\end{abstract}

\section{Giant Right Coronary Artery to Coronary Sinus Fistula}

Running Title: Giant Coronary Artery Fistula

Authors:

Lamees Ibrahim El Nihum, BS ${ }^{1,2}$, M. Mujeeb Zubair, MD ${ }^{3}$, Ponraj Chinnadurai, MBBS, MMST ${ }^{4}$, Thomas E. MacGillivray, $\mathrm{MD}^{1}$

1. DeBakey Heart \& Vascular Center, Houston Methodist Hospital, Houston, TX

2. Texas A\&M College of Medicine, Bryan, TX, USA

3. Cedars-Sinai Medical Center, Los Angeles, CA, USA

4. Siemens Medical Solutions USA, Inc., Malvern, PA, USA

Funding: The authors report no forms of financial support involved in the production of this case report.

Consent/Ethics Approval Statement: The authors attest they are in compliance with human studies committees and animal welfare regulations of the authors' institutions and Food and Drug Administration guidelines, including patient consent where appropriate.

N/A: IRB approval and clinical trial registration are not applicable for our study.

Disclosures: Ponraj Chinnadurai is a Senior Key Expert at Advanced Therapies Division, Siemens Medical Solutions USA.

\section{Corresponding Author:}

Thomas E. MacGillivray, MD

DeBakey Heart and Vascular Center

Houston Methodist Hospital

6550 Fannin Street

Smith Tower, Suite 1401

Houston, TX 77030 
Tel: $281-507-8361$

tmacgillivray@houstonmethodist.org

Word Count: 300

Twitter Handle: @MujeebZubair

\section{Glossary of Abbreviations:}

$\mathrm{CS}=$ coronary sinus

PDA $=$ posterior descending artery

$\mathrm{RA}=$ right atrium

$\mathrm{RCA}=$ right coronary artery

Abstract: Coronary artery fistulas are rare congenital anomalies for which the ideal management strategies remain under study, with surgical repair being the mainstay of treatment in complex, aneurysmal fistulas.

Consent/Ethics Approval Statement: The authors attest they are in compliance with human studies committees and animal welfare regulations of the authors' institutions and Food and Drug Administration guidelines, including patient consent where appropriate.

N/A: IRB approval and clinical trial registration are not applicable for our study.

Text

A 59-year-old woman presented with right heart enlargement. Computed tomography angiography revealed a $22 \mathrm{~mm}$ right coronary artery (RCA) draining into an enlarged coronary sinus (CS) (Figures 1-3) . Cardiac catheterization revealed a Qp:Qs of 2.0. We proceeded with surgery ${ }^{1}$. Intraoperatively, a thrill was palpable upon the RCA and right atrium (RA) (Figure 4). Circumferential control around the RCA origin was achieved as it emerged from the right sinus of Valsalva into the right ventricular fat. The distal ascending aorta and vena cavae were cannulated. Cardiopulmonary bypass was initiated. The aorta was cross-clamped and a bulldog clamp was placed on the proximal RCA. Del Nido cardioplegia was delivered into the ascending aorta and electrical arrest achieved. Tourniquets were secured around the vena cavae. The distal RCA was opened just proximal to its junction with the CS. An opening into the CS was confirmed by passing a probe from the RCA into the CS, and closed with a bovine pericardium patch using continuous 6-0 Prolene. The right coronary arteriotomy was closed with two layers of 6-0 Prolene. An end-to-side anastomosis of a saphenous vein graft to the posterior descending artery (PDA) was performed using continuous 7-0 Prolene. The RA was opened. Cardioplegia was infused through the vein graft into the PDA, and the CS was inspected to confirm no flow into the CS. The RA was closed. A side-to-side anastomosis of the vein graft to the right ventricular marginal artery was performed using a double diamond technique and continuous 7-0 Prolene. The RCA origin was triply ligated using two separate 4-0 Prolene sutures with a 2-0 silk ligature in between. A single proximal anastomosis to the ascending aorta was performed using a $4.0 \mathrm{~mm}$ aortic punch and continuous 6-0 Prolene. At the procedure's close, mixed venous oxygen saturation was $76 \%$. Six months later the patient was doing well.

\section{References}

1. Rowse PG, Said SM. The need for multiple bypass grafts in repair of right coronary artery-to-coronary sinus fistulas. Ann Thorac Surg, 2018. 106(6):p.e299-e301.

\section{Figure Legends}

Figure 1. RCA-CS Fistula. Three-dimensional reconstruction of computed tomography angiography of giant RCA-CS fistula. $C S=$ coronary sinus; $L A D=$ left anterior descending; $L C X=$ left circumflex; $L M$ $=$ left main; $P D A=$ posterior descending artery; $P L V=$ posterior left ventricular; $R C A=$ right coronary artery. 
Figure 2. RCA-CS Fistula Origin. $C S=$ coronary sinus; $L A D=$ left anterior descending; $L C X=$ left circumflex; $L M=$ left main; $P D A=$ posterior descending artery; $P L V=$ posterior left ventricular; $R C A=$ right coronary artery.

Figure 3. RCA-CS Fistula Drainage. $C S=$ coronary sinus; $L A D=$ left anterior descending; $L C X=$ left circumflex; $L M=$ left main; $P D A=$ posterior descending artery; $P L V=$ posterior left ventricular; $R C A$ $=$ right coronary artery.

Figure 4. Intraoperative Image. Giant right coronary artery to coronary sinus fistula with palpable thrill.

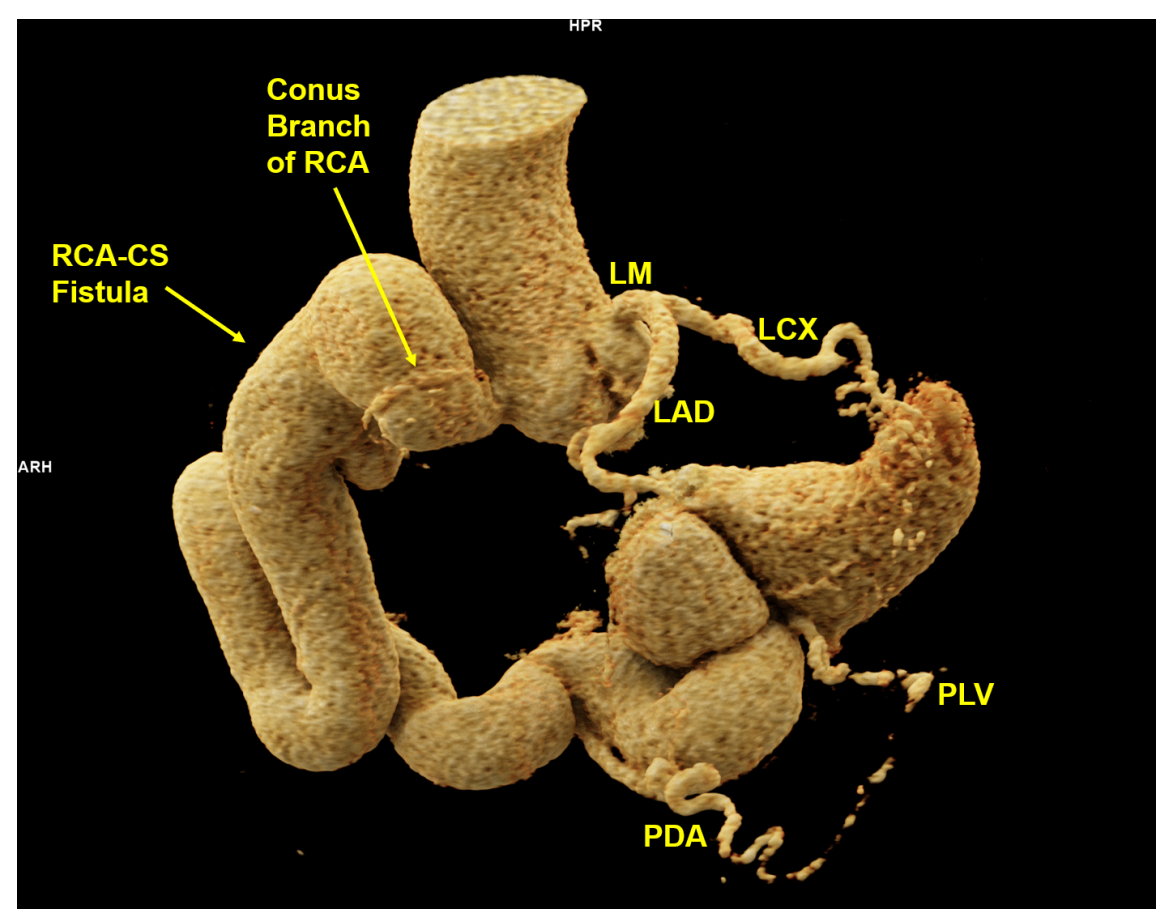



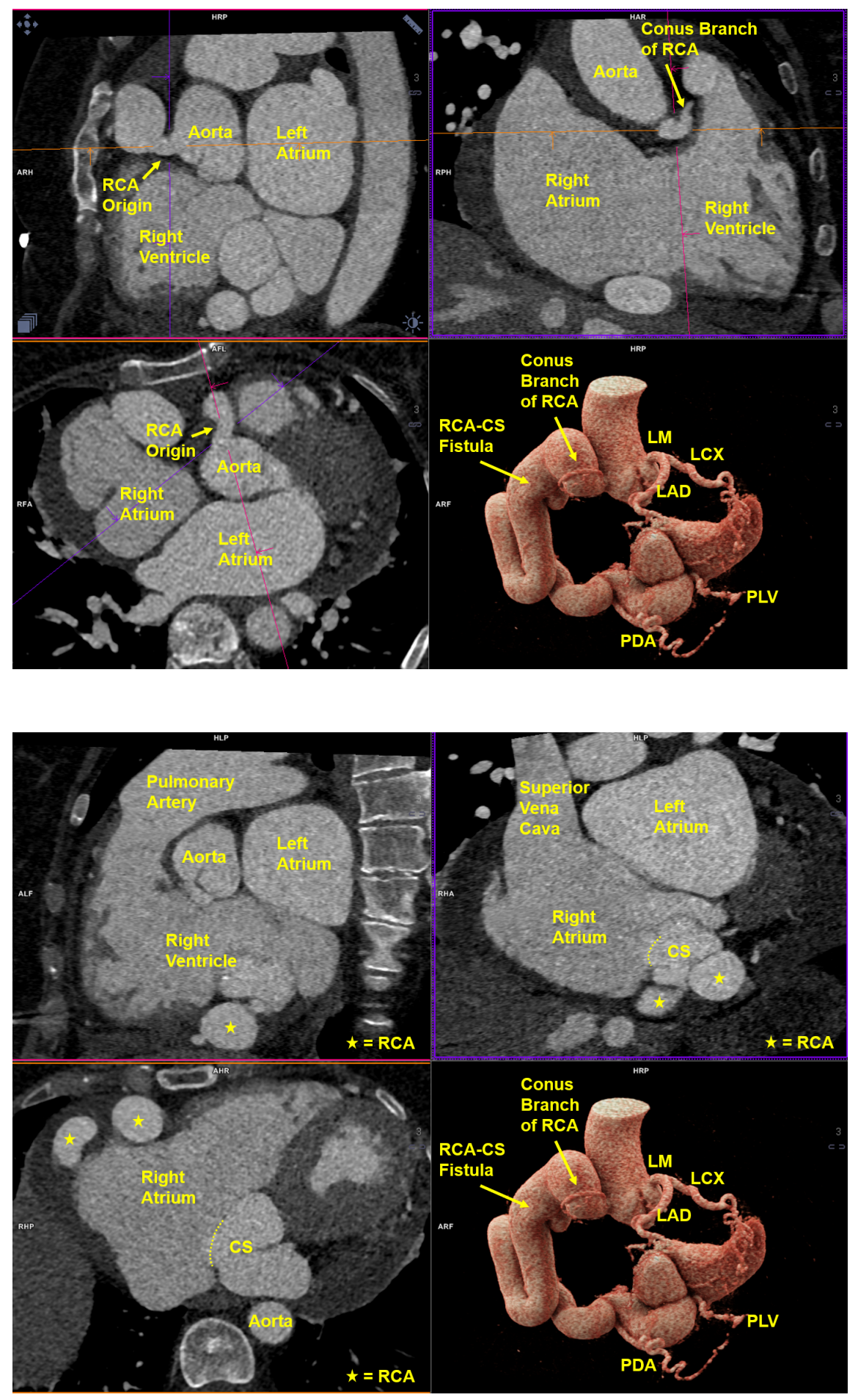


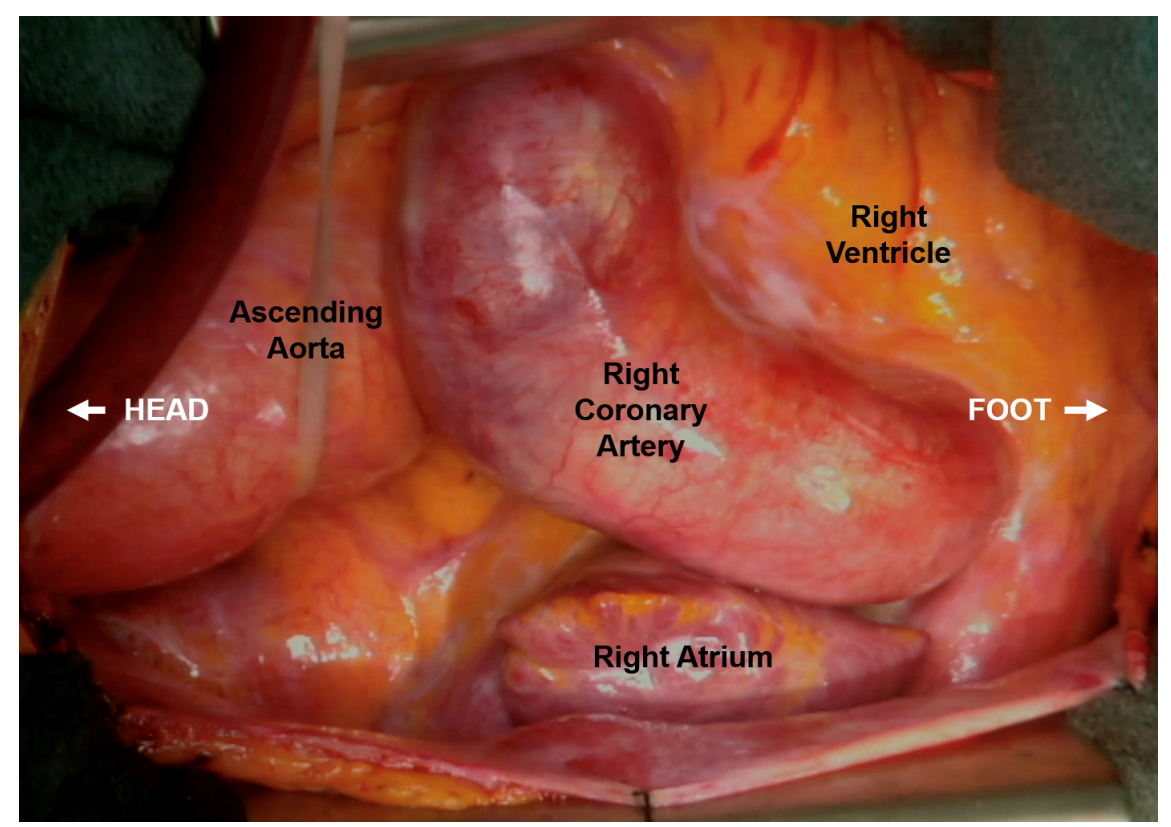

